Journal of Mathematics and Informatics

Vol. 14, 2018, 11-16

ISSN: 2349-0632 (P), 2349-0640 (online)

Published 20 August 2018

www.researchmathsci.org

DOI: http://dx.doi.org/10.22457/jmi.v14a2

Journal of

Mathematics and

Informatics

\title{
Reduced Second Hyper-Zagreb Index and its Polynomial of Certain Silicate Networks
}

\author{
V.R.Kulli \\ Department of Mathematics, \\ Gulbarga University, Gulbarga 585106, India \\ e-mail:vrkulli@gmail.com
}

Received 8 July 2018; accepted 15 August 2018

Abstract. We introduce the reduced second hyper-Zagreb index of a graph. Considering this index, we define the reduced second hyper-Zagreb polynomial of a graph. Also we define the reduced second Zagreb polynomial of a graph. In this paper, we compute the reduced second hyper-Zagreb index and its polynomial of certain families of networks such as silicate and chain silicate networks. Also we determine the reduced second Zagreb polynomial of certain silicate networks.

Keywords: reduced second hyper-Zagreb index, silicate network.

AMS Mathematics Subject Classification (2010): 05C05, 05C07, 05C35

\section{Introduction}

Let $G$ be a finite, simple, connected graph with vertex set $V(G)$ and edge set $E(G)$. The degree $d_{G}(v)$ of a vertex $v$ is the number of vertices adjacent to $v$. We refer [1], for other undefined notations and terminologies.

A molecular graph is a graph such that its vertices correspond to the atoms and edges to the bonds. Chemical Graph Theory is a branch of mathematical chemistry, which has an important effect on the development of Chemical Sciences. Several topological indices have been considered in Theoretical Chemistry and have found some applications.

Recently Furtula et al. proposed the reduced second Zagreb index, defined as [2]

$$
R M_{2}(G)=\sum_{u v \in E(G)}\left(d_{G}(u)-1\right)\left(d_{G}(v)-1\right) .
$$

Recently, some new reduced indices were studied, for example, in $[3,4,5,6,7]$.

Considering the reduced second Zagreb index, we introduce the reduced second Zagreb polynomial of a graph $G$ as

$$
R M_{2}(G, x)=\sum_{u v E(G)} x^{\left(d_{G}(u)-1\right)\left(d_{G}(v)-1\right)} .
$$

We now introduce the reduced second hyper-Zagreb index of a graph $G$, defined as, 


$$
\operatorname{RHM}_{2}(G)=\sum_{u v E(G)}\left[\left(d_{G}(u)-1\right)\left(d_{G}(v)-1\right)\right]^{2} .
$$

Considering the reduced second hyper-Zagreb index, we introduce the reduced second hyper-Zagreb polynomial of a graph $G$ as

$$
\operatorname{RHM}_{2}(G, x)=\sum_{u v \in(G)} x^{\left[\left(d_{G}(u)-1\right)\left(d_{G}(v)-1\right)\right]^{2}} .
$$

Recently, some new topological indices were studied, for example, in $[8,9,10$, $11,12,13,14,15,16,17,18,19,20,21,22,23]$. Also some new polynomials were studied, for example, in [ 24, 25, 26 27, 28, 29, 30, 31].

In this paper, the reduced second Zagreb polynomial, reduced second hyperZagreb index and its polynomial of silicate and chain silicate networks are computed. For more information about silicate networks see [32].

\section{Results for silicate networks}

Silicate networks are obtained by fusing metal oxide or metal carbonates with sand. A silicate network is symbolized by $S L_{n}$, where $n$ is the number of hexagons between the center and boundary of $S L_{n}$. A silicate network of dimension two is shown in Figure 1.

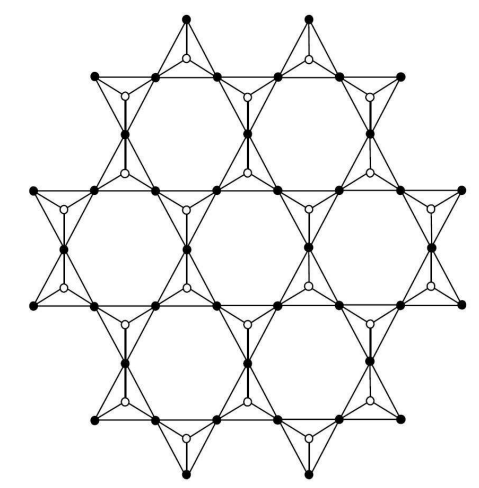

Figure 1: Silicate network of dimension two

Let $G$ be the graph of a silicate network $S L_{n}$ with $\left|V\left(S L_{n}\right)\right|=15 n^{2}+3 n$ and $\left|E\left(S L_{n}\right)\right|=36 n^{2}$. By algebraic method, there are three types of edges in $G$ based on the degree of end vertices of each edge as in Table 1 .

\begin{tabular}{cccc}
\hline$d_{G}(u), d_{G}(v) \backslash u v \square E(G)$ & $(3,3)$ & $(3,6)$ & $(6,6)$ \\
\hline Number of edges & $6 n$ & $18 n^{2}+6 n$ & $18 n^{2}-12 n$ \\
\hline
\end{tabular}

Table 1: Edge partition of $S L_{n}$

Theorem 1. The reduced second Zagreb index and its polynomial of a silicate network $S L_{n}$ are

(i) $\quad R M_{2}\left(S L_{n}\right)=630 n^{2}+216 n$.

(ii) $\quad R M_{2}\left(S L_{n}, x\right)=6 n x^{4}+\left(18 n^{2}+6 n\right) x^{10}+\left(18 n^{2}-12 n\right) x^{25}$.

Proof: Let $G=S L_{n}$ be the graph of a silicate network. 
Reduced Second Hyper-Zagreb Index and its Polynomial of Certain Silicate Networks

(i) By using equation (1) and Table 1, we obtain

$$
\begin{aligned}
R M_{2}\left(S L_{n}\right) & =\sum_{u v E(G)}\left(d_{G}(u)-1\right)\left(d_{G}(v)-1\right) \\
& =(3-1)(3-1) 6 n+(3-1)(6-1)\left(18 n^{2}+6 n\right)+(6-1)(6-1)\left(18 n^{2}-12 n\right) \\
& =630 n^{2}-216 n .
\end{aligned}
$$

(ii) By using equation (2) and Table 1, we obtain

$$
\begin{aligned}
R M_{2}\left(S L_{n}, x\right) & =\sum_{u v \in E(G)} x^{\left(d_{G}(u)-1\right)\left(d_{G}(v)-1\right)} \\
& =6 n x^{(3-1)(3-1)}+\left(18 n^{2}+6 n\right) x^{(3-1)(6-1)}+\left(18 n^{2}-12 n\right) x^{(6-1)(6-1)} \\
& =6 n x^{4}+\left(18 n^{2}+6 n\right) x^{10}+\left(18 n^{2}-12 n\right) x^{25}
\end{aligned}
$$

Theorem 2. The reduced second hyper-Zagreb index and its polynomial of a silicate network $S L_{n}$ are

(i) $\quad R H M_{2}\left(S L_{n}\right)=13050 n^{2}-6804 n$.

(ii) $\quad \operatorname{RHM}_{2}\left(S L_{n}, x\right)=6 n x^{16}+\left(18 n^{2}+6 n\right) x^{100}+\left(18 n^{2}-12 n\right) x^{625}$.

Proof: Let $G=S L_{n}$ be the graph of a silicate network.

(i) By using equation (3) and Table 1, we obtain

$$
\begin{aligned}
R H M_{2} & \left(S L_{n}\right)=\sum_{u v E(G)}\left[\left(d_{G}(u)-1\right)\left(d_{G}(v)-1\right)\right]^{2} \\
& =[(3-1)(3-1)]^{2} 6 n+[(3-1)(6-1)]^{2}\left(18 n^{2}+6 n\right)+[(6-1)(6-1)]^{2}\left(18 n^{2}-12 n\right) \\
& =13050 n^{2}-6804 n .
\end{aligned}
$$

(ii) By using equation (4) and Table 1, we obtain

$$
\begin{aligned}
R H M_{2} & \left(S L_{n}, x\right)=\sum_{u v \in E(G)} x^{\left[\left(d_{G}(u)-1\right)\left(d_{G}(v)-1\right)\right]^{2}} \\
& =6 n x^{[(3-1)(3-1)]^{2}}+\left(18 n^{2}+6 n\right) x^{[(3-1)(6-1)]^{2}}+\left(18 n^{2}-12 n\right) x^{[(6-1)(6-1)]^{2}} \\
& =6 n x^{16}+\left(18 n^{2}+6 n\right) x^{100}+\left(18 n^{2}-12 n\right) x^{625} .
\end{aligned}
$$

\section{Results for chain silicate networks}

We now consider a family of chain silicate networks. This network is symbolized by $C S_{n}$ and is obtained by arranging $n$ tetrahedral linearly, see Figure 2 .

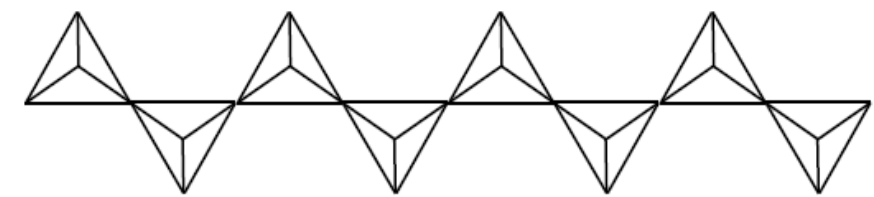

Figure 2: Chain silicate network

Let $G$ be the graph of chain silicate network $C S_{n}$ with $\left|V\left(C S_{n}\right)\right|=3 n+1$ and $\left|E\left(C S_{n}\right)\right|=6 n$. By algebraic method, $C S_{n}, n \square 2$, there are three types of edges based on the degree of end vertices of each edge as in Table 2.

\begin{tabular}{cccc}
\hline$d_{G}(u), d_{G}(v) \backslash u v \square E(G)$ & $(3,3)$ & $(3,6)$ & $(6,6)$ \\
\hline Number of edges & $n+4$ & $4 n-2$ & $n-2$ \\
\hline
\end{tabular}

Table 2: Edge partition of $C S_{n}$ 
Theorem 3. The reduced second Zagreb index and its polynomial of a chain silicate network $C S_{n}$ are

(i) $\quad R M_{2}\left(C S_{n}\right)=69 n-54$.

(ii) $\quad R M_{2}\left(C S_{n}, x\right)=(n+4) x^{4}+(4 n-2) x^{10}+(n-2) x^{25}$.

Proof: Let $G=C S_{n}$ be the graph of chain silicate network.

(i) By using equation (1) and Table 2, we deduce

$$
\begin{aligned}
R M_{2}\left(C S_{n}\right) & =\sum_{u v \in E(G)}\left(d_{G}(u)-1\right)\left(d_{G}(v)-1\right) \\
& =(3-1)(3-1)(n+4)+(3-1)(6-1)(4 n-2)+(6-1)(6-1)(n-2) \\
& =69 n-54 .
\end{aligned}
$$

(ii) By using equation (2) and Table 2, we deduce

$$
\begin{aligned}
R M_{2}\left(C S_{n}, x\right) & =\sum_{u v E(G)} x^{\left(d_{G}(u)-1\right)\left(d_{G}(v)-1\right)} \\
& =(n+4) x^{(3-1)(3-1)}+(4 n-2) x^{(3-1)(6-1)}+(n-2) x^{(6-1)(6-1)} \\
& =(n+4) x^{4}+(4 n-2) x^{10}+(n-2) x^{25} .
\end{aligned}
$$

Theorem 4. The reduced second hyper-Zagreb index and its polynomial of a chain silicate network $C S_{n}$ are

(i) $\quad \operatorname{RHM}_{2}\left(C S_{n}\right)=1041 n-1386$.

(ii) $\quad \operatorname{RHM}_{2}\left(C S_{n}, x\right)=(n+4) x^{16}+(4 n-2) x^{100}+(n-2) x^{625}$.

Proof: Let $G=C S_{n}$ be the graph of chain silicate network.

(i) By using equation (3) and Table 2, we deduce

$$
\begin{aligned}
R H M_{2} & \left(C S_{n}\right)=\sum_{u v E(G)}\left[\left(d_{G}(u)-1\right)\left(d_{G}(v)-1\right)\right]^{2} \\
& =[(3-1)(3-1)]^{2}(n+4)+[(3-1)(6-1)]^{2}(4 n-2)+[(6-1)(6-1)]^{2}(n-2) \\
& =1041 n-1386
\end{aligned}
$$

(ii) By using equation (4) and Table 2, we deduce

$$
\begin{aligned}
\operatorname{RHM}_{2}( & \left.C S_{n}, x\right)=\sum_{u \in E(G)} x^{\left[\left(d_{G}(u)-1\right)\left(d_{G}(v)-1\right)\right]^{2}} \\
& =(n+4) x^{[(3-1)(3-1)]^{2}}+(4 n-2) x^{[(3-1)(6-1)]^{2}}+(n-2) x^{[(6-1)(6-1)]^{2}} \\
& =(n+4) x^{16}+(4 n-2) x^{100}+(4 n-2) x^{625} .
\end{aligned}
$$

\section{Conclusion}

In this paper, the explicit formulas for the reduced hyper-Zagreb index and its polynomial of silicate and chain silicate networks are computed. These expressions can correlate the molecular structure of silicate and chain silicate networks to information about their physical structures.

\section{REFERENCES}

1. V.R.Kulli, College Graph Theory, Vishwa International Publications, Gulbarga, India (2012).

2. B.Furtula, I.Gutman and S.Ediz, On difference of Zagreb indices, Discrete Appl. Math., 178 (2018) 83-88. 
Reduced Second Hyper-Zagreb Index and its Polynomial of Certain Silicate Networks

3. I.Gutman, B.Furtula and C.Elphick, Three new/old vertex degree based topological indices, MATCH Commun. Math. Comput. Chem., 72 (2014) 617-682.

4. B.Horoldagva, L.Buyantoglokh and S.Dorjsembe, Difference of Zagreb indices and reduced second Zagreb index of cyclic graphs with cut edges, MATCH Commun. Math. Comput. Chem., 78 (2017) 337-350.

5. V.R.Kulli, On reduced Zagreb indices of polycyclic aromatic hydrocarbons and benzenoid systems, Annals of Pure and Applied Mathematics, 18(1) (2018).

6. V.R.Kulli, General reduced second Zagreb index of certain networks, submitted.

7. V.R.Kulli, Some multiplicative reduced indices of certain nanostructures, submitted.

8. V.R.Kulli, On $K$ indices of graphs, Int. J. Fuzzy Mathematical Archive, 10(2) (2016) 105-109.

9. V.R.Kulli, On $K$ coindices of graphs, Journal of Computer and Mathematical Sciences, 7(3) (2018) 107-112.

10. V.R.Kulli, On $K$-edge index of some nanostructures, Journal of Computer and Mathematical Sciences, 7(7) (2016) 373-378.

11. V.R.Kulli, On $K$ Banhatti indices and $K$ hyper-Banhatti indices of $V$-Phenylenic nanotubes and nanotorus, Journal of Computer and Mathematical Sciences, 7(6) (2016) 302-307.

12. V.R.Kulli, General topological indices of circumcoronene series of benzenoid, International Research Journal of Pure Algebra, 7(5) (2017) 748-753.

13. V.R.Kulli, Computation of some Gourava indices of titania nanotubes, Interational Journal of Fuzzy Mathematical Archive, 12(2) (2017) 75-81.

14. V.R.Kulli, Edge version of multiplicative atom bond connectivity index of certain nanotubes and nanotorus, International Journal of Mathematics and its Applications, 6(1-E) (2018) 977-982.

15. V.R.Kulli, Computing Banhatti indices of networks, International Journal of Advances in Mathematics, 2018(1) 2018) 31-40.

16. V.R.Kulli, Some new fifth multiplicative Zagreb indices of PAMAM dendrimers, Journal of Global Research in Mathematics, 5(2) (2018) 82-86.

17. V.R.Kulli, Multiplicative connectivity Banhatti indices of dendrimer nanostars, Journal of Chemistry and Chemical Sciences, 8(6) (2018) 964-973.

18. V.R.Kulli, Connectivity Revan indices of chemical structures in drugs, International Journal of Engineering Sciences and Research Technology, 7(5) (2018).

19. V.R.Kulli, Computation of $F$ reverse index and modified reverse indices of some nanostructure, Annals of Pure and Applied Mathematics, 18(1) (2018) 37-43.

20. V.R.Kulli, On augmented reverse index and its polynomial of certain nanostar dendrimers, International Journal of Engineering Sciences And Research Technology, 7(8) (2018) 237-243.

21. V.R.Kulli, On two arithmetic-geometric Banhatti indices of certain dendrimer nanostars, International Journal of Fuzzy Mathematical Archive, 16(1) (2018) 7-12.

22. V.R.Kulli and M.H.Akhbari, Multiplicative atom bond connectivity and multiplicative geometric-arithmetic indices of dendrimer nanostars, Annals of Pure and Applied Mathematics, 16(2) (2018) 429-436. 


\section{V.R.Kulli}

23. V.R.Kulli, B.Chaluvaraju and H.S.Baregowda, $K$-Banhatti and $K$ hyper-Banhatti indices of windmill graphs, South East Asian J. of Math. and Math. Sci., 13(1) (2017) 11-18.

24. V.R.Kulli, General Zagreb polynomials and F-polynomial of certain nanostructures, International Journal of Mathematical Archive, 8(10) (2017) 103-109.

25. V.R.Kulli, General fifth $M$-Zagreb indices and fifth $M$-Zagreb polynomials of PAMAM dendrimers, International Journal of Fuzzy Mathematical Archive, 13(1) (2017) 99-103.

26. V.R.Kulli, Certain topological indices and their polynomials of dendrimer nanostars, Annals of Pure and Applied Mathematics, 14(2) (2017) 263-268.

27. V.R.Kulli, Reverse Zagreb and reverse hyper-Zagreb indices and their polynomials of rhombus silicate networks, Annals of Pure and Applied Mathematics, 16(1) (2018) 47-51.

28. V.R.Kulli, Hyper-Revan indices and their polynomials of silicate networks, International Journal of Current Research in Science and Technology, 4(3) (2018).

29. V.R.Kulli, Revan indices and their polynomials of certain rhombus networks, International Journal of Current Research in Life Sciences, 7(5) (2018) 2110-2116.

30. V.R.Kulli, On ve-degree indices and their polynomials of dominating oxide networks, Annals of Pure and Applied Mathematics, 18(1) (2018) 1-7.

31. V.R.Kulli, Computing the F-ve-degree index and its polynomial of dominating oxide and regular triangulate oxide networks, International Journal of Fuzzy Mathematical Archive, 16(1) (2018) 1-6.

32. S.Wang, J.B.Liu, C.Wang and S.Hayat, Further results on computation of topological indices of certain networks, arXiv: 1605.00253v2 [math.Co] 5 May 2016, 1-18. 